\title{
Brazilian physicists community diversity, equity, and inclusion: A first diagnostic
}

\author{
Celia Anteneodo®* \\ Departamento de Física, Pontíficia Universidade Católica do Rio de Janeiro, \\ PUC-Rio, Rua Marquês de São Vicente 225, 22451-900 Rio de Janeiro, RJ, Brazil \\ Carolina Brito $\odot^{\dagger}$ and Alan Alves-Brito $\odot$ \\ Instituto de Física, Universidade Federal do Rio Grande do Sul, \\ Avenida Bento Gonçalves, 9500, 91501-970 Porto Alegre, RS, Brazil \\ Simone Silva Alexandre $\odot$ \\ Departamento de Física, Universidade Federal de Minas Gerais, \\ Avenida Antônio Carlos, 6627, 31270-901 Belo Horizonte Minas Gerais, MG, Brazil \\ Beatriz Nattrodt D’Avila and Débora Peres Menezes $\circledast^{\ddagger}$ \\ Departamento de Física, CFM-Universidade Federal de Santa Catarina, \\ C.P. 476, CEP 88.040-900 Florianópolis, SC, Brazil
}

(Received 14 December 2019; accepted 21 May 2020; published 5 June 2020)

\begin{abstract}
We report the results of a survey applied to students and professionals in the area of physics in Brazil, pursuing to draw a portrait of the composition of this community in terms of the social markers of difference age, race, ethnicity, geographical origin, sex, gender, sexual orientation, and disabilities. The main goal was to quantify the representativeness of different groups in the community and to detect motivations and difficulties encountered by each group throughout their studies and career. This survey was open to the members of the Brazilian Physics Society from July to September 2018. Our outcomes reveal that (i) the Brazilian physicists community is poorly diverse even in comparison with the population composition, (ii) the main obstacle to pursue the career is socioeconomic vulnerability, and (iii) harassment is high in our society, being more pronounced among women. We hope that these results will be useful to scientific and educational institutions to develop different strategies and policies to change this current situation.
\end{abstract}

DOI: 10.1103/PhysRevPhysEducRes.16.010136

\section{INTRODUCTION}

The enriching role of a diverse environment for critical education and the advancement of knowledge has been demonstrated in several studies. Indeed, diversity, equity, and inclusion can increase creativity and contribute to individual and collective development [1-3], besides providing equal opportunities and avoiding the loss of talented people. Through new concepts and different perspectives, education and science can benefit and, reciprocally, exert positive feedback in favor of changing the observed picture of inequality [4-6]. Intercultural diversity is also seen as

*celia.fis@puc-rio.br

carolina.brito@ufrgs.br

debora.p.m.26@gmail.com

Published by the American Physical Society under the terms of the Creative Commons Attribution 4.0 International license. Further distribution of this work must maintain attribution to the author(s) and the published article's title, journal citation, and DOI. essential for critical thinking [7]. All this is especially desirable in a country like Brazil, whose economy is one of the strongest in the world and, at the same time, one of the most unequal [8].

As shown by many recent studies, Brazil is especially unequal and an extremely hostile country for women; lesbian, gay, bisexual, transgender, queer, and intersex (LGBTQI+) people; Afro-descendants and members of indigenous communities, as well as individuals with disabilities [9-12]. As a structural problem, the Brazilian scientific environment is not an exception to the rule, being dominated by white [13] and male people [14-16], implying underrepresentation of other groups, especially in leadership or prestigious positions, with respect to the demographic composition of the full population [16,17]. However, no records about Brazil's physics community exist beyond demographic markers as age, sex, and place of residence.

In view of all of the above, we pursued to draw a quantitative picture of the level of diversity, inclusion, and equity among the members of the Brazilian Physical 
Society (SBF). Then, we conducted a survey, using the social markers age, race, ethnic, geographical origin, sex, gender, sexual orientation, and disabilities. The main goal of this paper is to present the initial characterization of the Brazilian physical community that emerges from the outcomes of the survey. Detecting motivations and difficulties faced by the physics community is essential to help define policies that can improve the quality of education, the formation of new human resources and, hence, the quality of research in the field.

This paper is organized as follows: after a brief description of the historical background and of how the data were obtained, we present the survey results. They are divided into four separate subsections: the profile of the respondents, motivation and difficulties during their studies and along their careers, the problems of harassment in the community, and the job market available for physicists. A summary and final remarks are then presented. The questionnaire is displayed in the Appendix.

\section{BACKGROUND}

Historically, physics education in Brazil has been the object of systematic study since the 1960s, strongly influenced by the implementation, in the United States and, soon after, in Latin America, of the Physical Science Study Committee project [18]. Since then, physics education in Brazil has undergone several transformations following the different historical periods of the country (military regime of 1964-1985; democratic period after the 1988 Constitution) until today, in which there is, for education, science, technology, and culture in general, a critical moment of setback and disbelief in scientific knowledge. Today, despite advances and setbacks, the area of physics education in Brazil is well consolidated, encompassing varied thematic lines, which are not only focused on learning, but also on historical, political, philosophical, and social issues [19].

The SBF was founded on 14 July, 1966. It is a nonprofit association formed by physicists and scientists from related areas with activity or collaborations in Brazil. Its office is located in São Paulo city. In 2003, the gender relations commission was established by the SBF board of directors, aiming to check the possible existence of gender gaps in the academic environment of physicists and to implement policies to solve potential problems. Currently called the gender working group (GTG), it presents here a critical diagnostic concerning key aspects directly related to social markers of difference faced by physicists.

\section{DATA AND METHODS}

\section{A. Main questions}

The main questions that guide this study are the following: How diverse is the physics community? What attracts people to pursue this career? What are the main difficulties in becoming and working as a physicist? To what extent are sexual and moral harassment problems in this community? How are physicists placed in the job market? Answers to these questions may give hints that will help us to build, on the basis of quantitative data, public policies for science education and outreach more sensitive to diversity, inclusion, and equity.

\section{B. Survey}

The questionnaire presented to the SBF members (initially posed in Portuguese) is translated in the Appendix. It was built in GoogleForms to be filled anonymously, and was open for responses from July 3 to September 21, 2018. It consisted of various sets of questions, most of them in multiple-choice format, to facilitate the participation of respondents as well as data collection and analysis. A window for free comments was also available alongside most questions. This questionnaire was inspired mainly in a survey applied in 2018 to students of federal institutions [20], to make a census of that universe. It was chosen as a basis (in alternative to surveys undertaken by foreign institutions) because the terminology was in Portuguese and followed the official Brazilian census, which was particularly important concerning race and gender issues. We adapted the survey to our particular questions and a preliminary version was tested (as a pilot survey) in a small group of about 20 people that gave us feedback to improve the questions. It was also revised by the members of the working group of under-represented people of the SBF. Then we launched the survey within the whole community for volunteer anonymous participation. It was advertised by emails sent to the SBF members but, as its anonymous character was preserved, we cannot guarantee that people from outside the community have not replied.

As stated above, the terminology followed the official Brazilian census and less common terms were defined in the questionnaire. The Brazilian Institute of Geography and Statistics (IBGE), since the 19th century, is the official agency responsible to define census categories, which are based on a skin color continuum, ranging from individuals with very fair skin to those individuals with a very dark one. We have adopted IBGE official categories: branca (white), preta (black), parda, amarela (yellow: translated as Asian) and indigena (indigeneous). In Brazil, there is a common distinction between people who self-declare as black, with a darker tone of skin and parda, with lighter skin tones [21].

After discarding a few incorrectly filled forms (less than $1 \%$ ), the number of valid ones was 1695, which is impressive given there were 3875 effective SBF members at the time of the survey. From this set, multiple-choice answers were counted within different groups characterized by the specific markers. 


\section{DATA ANALYSES AND RESULTS}

\section{A. Profile of the respondents}

In this section we address how diverse the physics community in Brazil is and how diversity changes when the career evolves. We first display information about the academic level attained. We then analyze diversity according to geographical origin and place of residence, race and ethnicity, sex, gender and sexual orientation, and disabilities.

\section{Academic degree}

In Table I, we show the composition of the population of 1695 respondents, with respect to their education level (highest attained academic degree). Let us remark that bachelor's in physics and physics education are both undergraduate degrees at the same level of education, and "related areas" refers to other majors in science, technology, engineering, and mathematics (STEM). Notice that the majority are graduate students, i.e., $66 \%$ and $19 \%$ hold a Ph.D. and a master's degree in physics (or related areas), respectively, while 9\% hold a degree in physics education or a bachelor's degree in physics (or related areas), and $6 \%$ are undergraduate students that have only finished high school studies. These values are compatible with the records of the SBF about the composition of members with annuity payment on time, also shown in Table I. The proportion of respondents is a bit larger among affiliates with a doctoral degree and lower among undergraduate students [hence, those with a high school (HS) degree].

\section{Geographical aspects}

With regard to geographical origin (place of birth) and current place of residence, the matrix in Fig. 1 displays the number of people in each state of Brazil (identified by a two letter code and ordered by increasing latitude of its capital). The population is concentrated in the south and southeast regions and there is also a nucleus in the northeast including and above Pernambuco (PE). One also observes

TABLE I. Composition of respondents according to academic degree, compared to the composition of SBF affiliates. (Bachelor's and physics education are undergraduate degrees at the same level of education.)

\begin{tabular}{lccccr}
\hline \hline & \multicolumn{2}{c}{ Respondents } & & \multicolumn{2}{c}{ SBF members } \\
\cline { 2 - 3 } Degree & Number & $\%$ & & Number & $\%$ \\
\hline High school & 104 & 6 & & 505 & 13 \\
Bachelor's & 67 & 2 & & 279 & 5 \\
Physics education & 94 & 7 & & 59 & 4 \\
Master's & 314 & 19 & & 708 & 18 \\
Doctoral & 1116 & 66 & & 2324 & 60 \\
Total & 1695 & 100 & & 3875 & 100 \\
\hline \hline
\end{tabular}

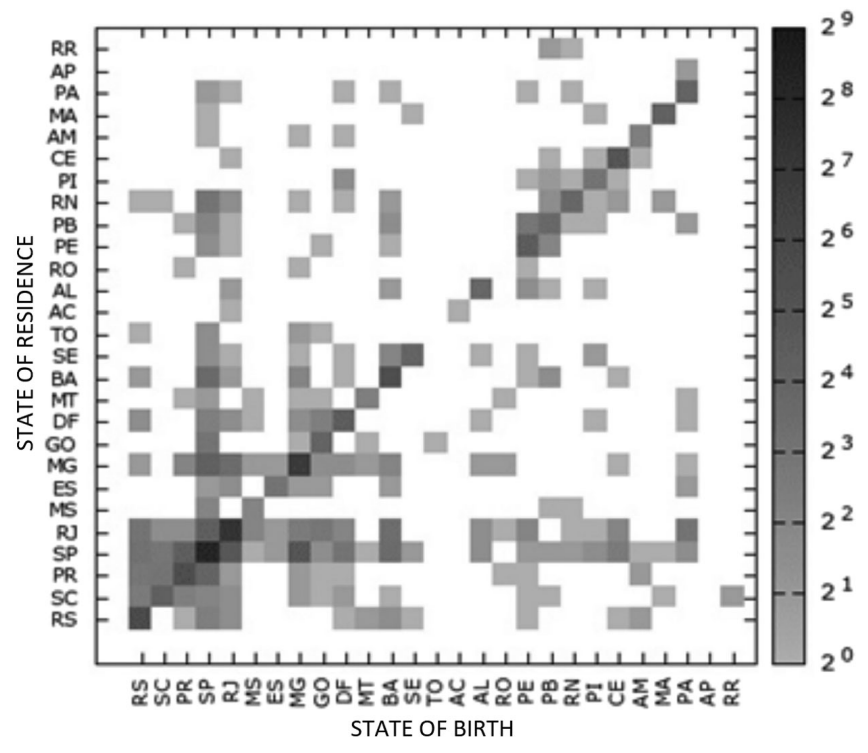

FIG. 1. Current state of residence versus state of birth. The gray scale represents the number of individuals. Brazilian states (two letter code) were ordered by latitude of their capital. From the respondents, 1594 are Brazilian and 1659 live in Brazil.

that there is little mobility of physicists in Brazil in general, probably due to the availability of many universities in each state. The matrix highlights migration towards and from the states of São Paulo (SP) and Rio de Janeiro (RJ), which are those with the largest gross regional product (GRP) per capita [22], while the other two more populated States of Minas Gerais (MG) and Bahia (BA) display predominantly migration from, rather than migration to. A large mobility is also observed within the three states of the south (i.e., RS, $\mathrm{SC}$ and $\mathrm{PR}$ ), alongside $\mathrm{SP}$ and $\mathrm{RJ}$ in the southeast region, and also within a few states in the northeast with the epicenter at PE.

\section{Race or ethnicity}

The (self-declared) ethnic composition of the community is presented in Fig. 2(a). Among the respondents, 30\% declared to be nonwhite (including black, parda, indigenous, Asian, and 2\% who declared "other") while $9 \%$ preferred not to answer or classify themselves. This information is not available in SBF records. As a reference, in Brazil, black and parda people constitute 54\% of the population [21]. Apart from that, the racial and ethnic statistics produced by the IBGE shows that Brazil is not a racial democracy at all; on average, white people in Brazil have the highest salaries and face less unemployment [23].

Figure 3 (top) shows the percentage of people that attained each degree decomposed by racial or ethnic groups. This profile puts into evidence the neat tendency of a lower proportion of black and parda people with the progression in the career. A similar trend has been detected in the STEM field in Brazil, where black and parda people 
(a)
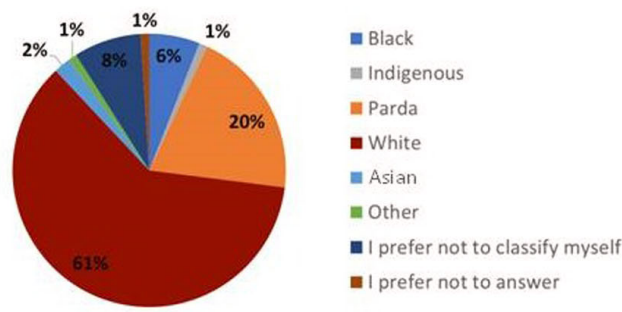

(b)

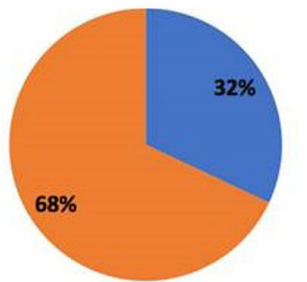

a Female

Male

w Other (less than $1 \%)$

(c)

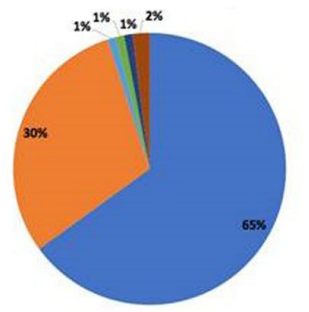

m Cisgender Man

= Transexual Man (less than $1 \%$ )

wisgender Woman

- Transexual Woman (less than 1\%)

w Non Binary

in Other

I prefer not to answer

I I prefer not to classify myself

(d)

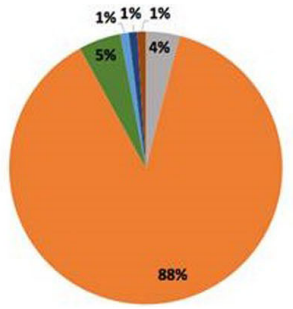

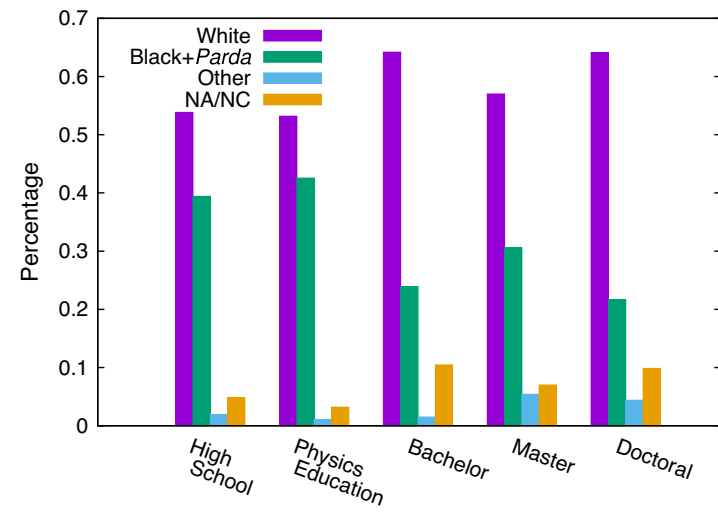

Maximum Degree Obtained

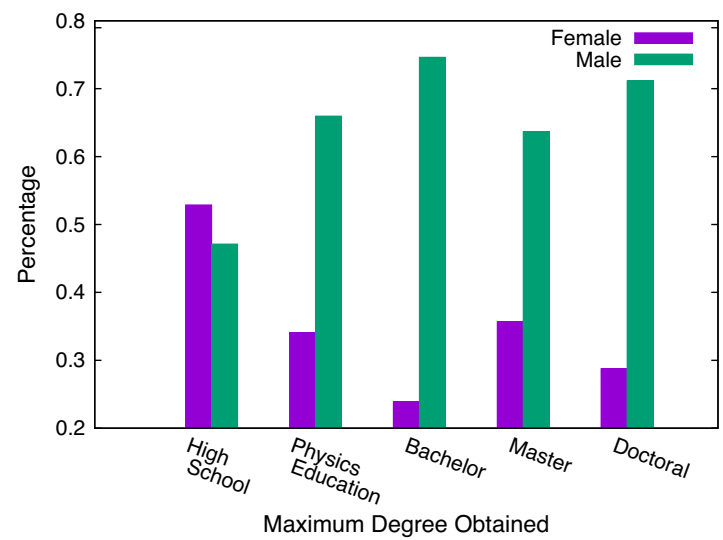

FIG. 3. Percentage of respondents vs highest degree attained, separated by race or ethnicity group (top) and by sex (bottom). In the legend, NA/NC = prefer not to answer or classify themselves. Recall that physics education and bachelor's correspond to undergraduate degrees at the same level.

stage (both bachelor's and physics education). At the level of graduate studies, the same trend is observed, with a decreasing proportion of women finishing Doctoral studies than master's ones. These profiles outline what is called the "scissors effect" with respect to sex, many times observed in Brazil [14-16] and abroad [6,24,25]. Let us call attention to the similarity of this profile and that observed in the upper panel of Fig. 3 with respect to white and black and parda.

A noticeable feature is that there are more people from underrepresented categories (in the cases of both sex and race) with a degree in physics education than with a bachelor's degree in physics. This may be related to the necessity to attain a degree that allows to enter earlier in the job market, although high school teachers in Brazil are badly paid in comparison with professionals in higher education institutions. Another trace of these underrepresented groups is that their proportion with a master's degree is higher than with a bachelor's degree, but similar to the proportion with degree in physics education, suggesting that although the initial choice was to follow the education career, they finally opted to pursue graduate studies. 
In sum, the majority of the respondents were white heterosexual men, as previously observed in other scientific communities $[6,13,24]$. Scientists who identify themselves as LGBT are a minority within the respondents. Consequently, they can feel themselves marginalized in different ways. In addition, previous international studies have shown that the campus environment can be quite LGBT phobic, especially for transgender individuals [26,27]. It is also worth noting that in Brazil, for instance, the life expectancy of a transgender individual (measured in 2013) was less than half that of the Brazilian population $[28,29]$.

\section{Disabilities}

When asked about disabilities, 1590 declared none. That is, only $6.2 \%$ of the respondents declared to bear a disability. Among them, the most common (not excluding) answers were low or abnormal vision (61 answers), physical and motor limitations (27), global developmental disorder (7), and among "others" the most frequent case was bipolar disorders (7). Among those who declared to have some disability, we found $27 \%$ women, a bit below the population proportion. The percentage with disabilities agrees with that found within the Brazilian population, according to IBGE [30], when asking about some type of deficiency (auditory, visual, physical or intellectual). Like in the physics community, more than half of the cases correspond to visual deficiencies. Although not shown in the tables, $41 \%$ within the group bearing some type of deficiency declared that they reached the highest degree in their career as fast as other colleagues. A more detailed investigation of the difficulties associated with specific disabilities should be made in order to diagnose whether the Brazilian institutions are prepared to receive students, researchers, and staff with disabilities. The survey shows that they tend to progress only slightly slower than the other respondents.

\section{B. Motivations}

The survey also aimed to identify the motivations for choosing a career in physics. This section is devoted to present the related data.

The respondents were asked to indicate the level of identification (very much, little or not at all) with several given possible motivations for choosing physics. The alternatives presented in the list were not excluding, so that multiple choices could be selected.

Figure 4 shows the histograms of the number of responses, for each motivation and level of identification. The three main motivating factors are (i) ease in mathematics at school, (ii) affinity for physics at school, and (iii) desire to take part in the progress of science. A high score obtained in mathematics at school was previously identified as an indicator of pursuing careers in STEM field with high probability [31]. Social and economic aspects, such as future salaries and social recognition, rarely appear
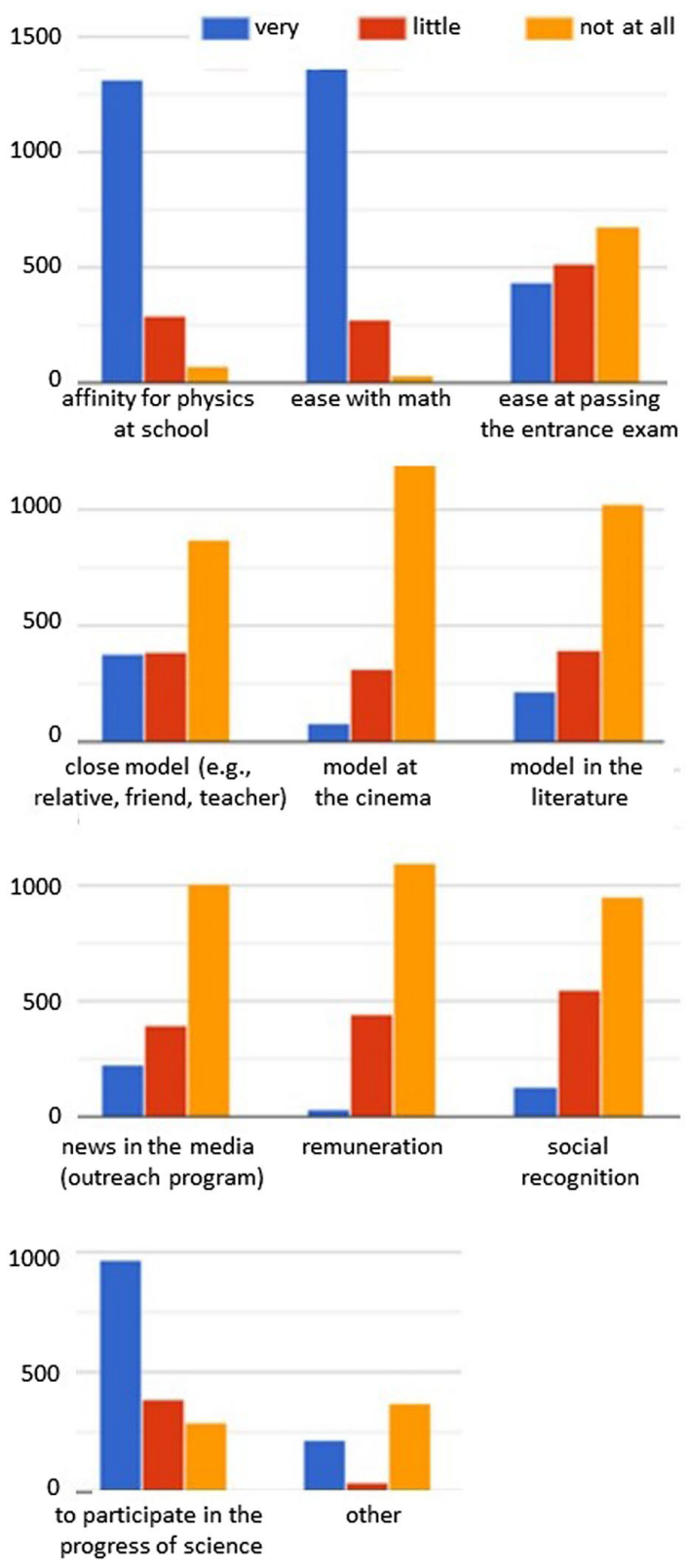

FIG. 4. Motivations for choosing physics. Histograms showing the number of (nonexclusive) responses associated with each possible motivation given in a list, according to the level of identification (very, little, not at all). Horizontal lines are drawn as references.

as career main motivations. It was also asked whether models of scientists in the literature, cinema, or family environment provided a motivation to pursue a career in physics. In most cases the answer was negative, as can be seen in Fig. 4, perhaps due to the absence of positive models.

The respondents could also indicate other possibilities not listed in the survey. Only 231 respondents indicated at least one spontaneous (not induced) motivation. The more popular ones are curiosity (33), teaching (30), knowledge (30), 


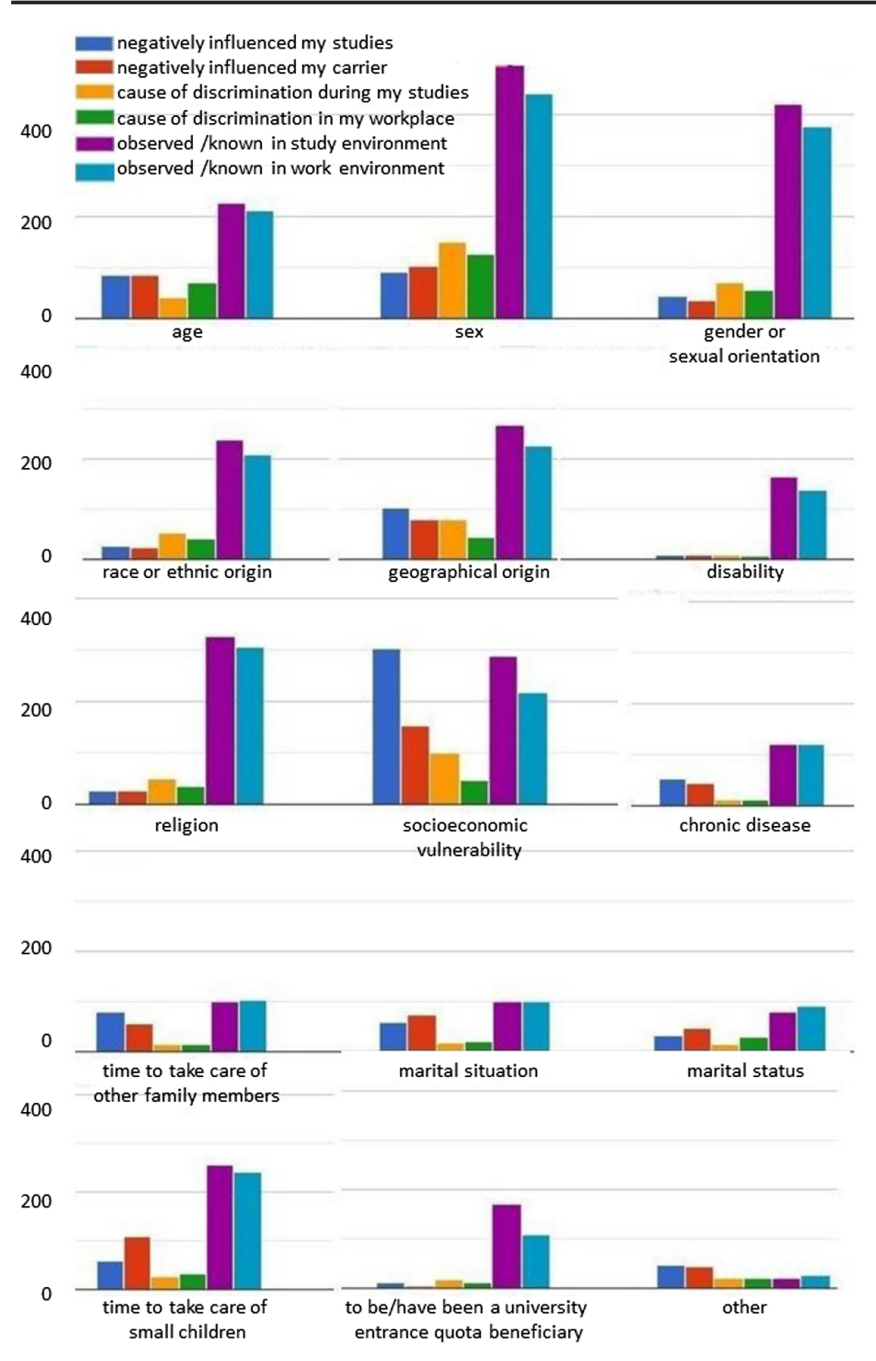

FIG. 5. Causes of difficulties. Number of (nonexclusive) responses for each factor associated with negative influence or discrimination of the respondent or colleagues given in the caption. Horizontal lines are drawn as references.

understanding (29), passion or pleasure (16), challenge (14), job opportunity (12), and routine freedom (7).

\section{Detecting difficulties}

One of the main purposes of the survey was to identify obstacles in the studies and/or career of the respondents. Concerning this issue, respondents were asked to identify (in a given list) the factors that negatively influenced their studies and/or career, as well as the factors identified as a cause of discrimination experienced by them in their study and/or work environment. The respondents were also requested to indicate the presumed causes of discrimination suffered by colleagues in the study or work environment, whenever observed or known.

Figure 5 shows histograms of the number of (nonexcluding) answers. These plots put into evidence that the main difficulty is related to socioeconomic vulnerability.
TABLE II. Percentage of people (within each group) that felt negative influence or discrimination due to the causes in the first row.

\begin{tabular}{lcccc}
\hline \hline & \multicolumn{4}{c}{ Causes } \\
\cline { 2 - 5 } & Race or color & Socioeconomic & Religious & Geographic \\
\hline White & $0.4 \%$ & $18.6 \%$ & $4.6 \%$ & $0.5 \%$ \\
Parda & $7.7 \%$ & $32.9 \%$ & $7.9 \%$ & $28.8 \%$ \\
Black & $45.5 \%$ & $49.4 \%$ & $14.3 \%$ & $31.2 \%$ \\
\hline \hline
\end{tabular}

Even in the subgroup of those who marked the other category, there are various specifications related to social or economic issues. As an example: necessity of work, family needs, flaws in the education, living far away from the university.

It is noteworthy that a large percentage of respondents have already observed or are aware of discrimination of colleagues in the study (lilac bar) and work (light blue bar) environments, with respect to various issues: sex, gender or sexual orientation, race or ethnicity, socioeconomic status, geographical origin, child care, and religion. This stands in contrast with the self-perception of the interviewees of feeling discriminated against, which may be related to the fact that those who suffer more are underrepresented in the community, hence in the population of respondents.

For instance, among women, $46.7 \%$ indicated a negative influence or discrimination due to sex, while that percentage falls to only $1.2 \%$ for men. In Table II, we present details for the more numerous categories of race or ethnicity, where we show the percentage of people in each group that identified some of the listed causes as having a negative impact. It is evident that parda people feel a more negative impact than white people with respect to the listed possible causes, a portrait which is even worse for black people.

\section{Harassment}

As one of the main difficulties encountered, the issue of harassment deserves a careful and separate treatment. This section is devoted to discussing to what extent harassment affects the community and which are the most attained groups.

The general percentages of respondents reporting to be a victim of sexual or moral harassment are summarized in Fig. 6. Moral harassment means workplace or school bullying, in the sense described in Ref. [32]. The questions in the survey were restricted to vertical descendent harassment in order to restrict the questions specific situations that are more easily identifiable. Almost $12 \%$ of respondents reported having suffered sexual harassment, while an astonishing $38 \%$ felt to have been a victim of moral harassment.

We also analyze the percentage of yes and no responses within each category of race or ethnicity and sex or gender, 


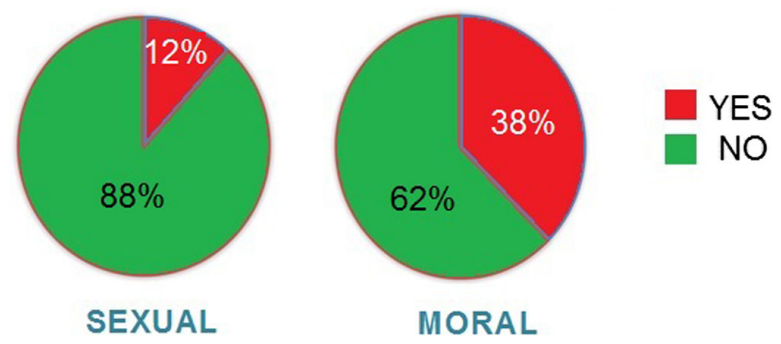

FIG. 6. Percentage of respondents reporting sexual or moral harassment.

in order to identify the more vulnerable ones. Table III exhibits the characterization of the universe of those who reported having suffered (or not) sexual harassment (12\% in the total population). The percentage of yes answers is much higher within the female group (32\%) than in the male group (2\%). Comparing the different subgroups of the female universe, the answers are rather homogeneous, except for the Asian women. A recent review summarizes the numbers of sexual harassment found in previous studies, showing that the percentage ranges from $30 \%$ up to $70 \%$ among women, in different fields and at different levels of the career [33], indicating that this is a serious problem in many other communities.

Table IV shows the corresponding values of the case of moral harassment, where $38 \%$ of respondents answered yes. In this case, the numbers are alarming also in the male group (31\%), but among females, the numbers are even higher (52\%). In all subgroups of the female universe, the percentages of yes answers are higher than in the whole population. In the male universe they are smaller except in the black and other subgroups.

In Table V, the numbers represent the total of respondents about sexual and moral harassment in each subgroup of gender and sexual orientation. Only cases with more than five answers are shown. This table also puts into

TABLE III. Number and percent of people who reported having suffered sexual harassment, within the subgroups of race and sex. Composition of respondents according to academic degree, compared to the composition of SBF affiliates.

\begin{tabular}{|c|c|c|c|c|c|c|}
\hline \multirow[b]{3}{*}{ Race or ethnicity } & \multicolumn{6}{|c|}{ Sex } \\
\hline & \multicolumn{3}{|c|}{ Female } & \multicolumn{3}{|c|}{ Male } \\
\hline & Yes & No & $\%$ Yes & Yes & No & $\%$ Yes \\
\hline Black & 14 & 23 & 38 & 2 & 59 & 3 \\
\hline Indigenous & 1 & 3 & 25 & 0 & 6 & 0 \\
\hline Parda & 28 & 60 & 32 & 6 & 241 & 2 \\
\hline White & 114 & 233 & 33 & 17 & 678 & 2 \\
\hline Asian & 1 & 16 & 6 & 0 & 18 & 0 \\
\hline Other & 3 & 5 & 38 & 1 & 15 & 6 \\
\hline Prefer not to classify & 8 & 22 & 27 & 2 & 95 & 2 \\
\hline Prefer not to answer & 0 & 3 & 0 & 0 & 15 & 0 \\
\hline Total & 169 & 365 & 32 & 28 & 1127 & 2 \\
\hline
\end{tabular}

TABLE IV. Number and percentage of people who reported having suffered moral harassment (bullying), within the subgroups of race and sex.

\begin{tabular}{|c|c|c|c|c|c|c|}
\hline \multirow[b]{3}{*}{ Ethnicity or color } & \multicolumn{6}{|c|}{ Sex } \\
\hline & \multicolumn{3}{|c|}{ Female } & \multicolumn{3}{|c|}{ Male } \\
\hline & Yes & No & $\%$ Yes & Yes & No & $\%$ Yes \\
\hline Black & 19 & 18 & 51 & 25 & 36 & 41 \\
\hline Indigenous & 3 & 1 & 75 & 1 & 5 & 17 \\
\hline Parda & 42 & 46 & 48 & 81 & 166 & 33 \\
\hline White & 180 & 167 & 52 & 202 & 493 & 29 \\
\hline Asian & 7 & 10 & 41 & 2 & 16 & 11 \\
\hline Other & 4 & 4 & 50 & 10 & 6 & 63 \\
\hline Prefer not to classify & 19 & 11 & 63 & 33 & 64 & 34 \\
\hline Prefer not to answer & 2 & 1 & 67 & 3 & 12 & 20 \\
\hline Total & 276 & 258 & 52 & 357 & 798 & 31 \\
\hline
\end{tabular}

evidence the higher percentages of sexual and moral harassment in the non-cisgender population. Although the absolute numbers of non-cis populations are not very large, some features are striking. This is the case, for example, of the nonbinary female population, where all the six women report having suffered bullying and half of them sexual harassment. In the case of the male population, four of the seven respondents in the other category reported having suffered bullying. This proportion of $57 \%$ is almost twice that observed in the male population of cisgender men. The percentages of moral and sexual harassment are systematically higher in the nonheterosexual (both female and male) populations, except for case of cisgender homosexuals. In general, the data point to a higher incidence of moral and sexual harassment in populations that differ from the majority response profile regarding gender identity

TABLE V. Sexual and moral harassment by category of sex, gender identity, and sexual orientation. Only categories with at least one response are shown. "All" refers to all categories of sexual orientation.

\begin{tabular}{|c|c|c|c|c|c|c|}
\hline \multirow{3}{*}{ Sex, gender, orientation } & \multicolumn{6}{|c|}{ Harassment } \\
\hline & \multicolumn{3}{|c|}{ Sexual } & \multicolumn{3}{|c|}{ Moral } \\
\hline & Yes & No & $\%$ Yes & Yes & No & $\%$ Yes \\
\hline Female, Cis, All & 161 & 351 & 31 & 265 & 247 & 52 \\
\hline Female, Nonbinary, All & 3 & 3 & 50 & 6 & 0 & 100 \\
\hline Male, Cis, All & 25 & 1073 & 2 & 334 & 764 & 30 \\
\hline Male, Other, All & 1 & 6 & 14 & 4 & 3 & 57 \\
\hline Male, Not to classify, All & 1 & 24 & 4 & 9 & 16 & 36 \\
\hline Male, Not to answer, All & 1 & 18 & 5 & 8 & 11 & 42 \\
\hline Female, Cis, Heterosexual & 134 & 310 & 30 & 219 & 225 & 50 \\
\hline Female, Cis, Bisexual & 15 & 19 & 44 & 19 & 15 & 56 \\
\hline Female, Cis, Homosexual & 4 & 14 & 22 & 11 & 7 & 61 \\
\hline Female, Cis, Not to classify & 5 & 5 & 50 & 6 & 4 & 60 \\
\hline Male, Cis, Heterosexual & 21 & 971 & 2 & 294 & 698 & 30 \\
\hline Male, Cis, Bisexual & 0 & 22 & 0 & 9 & 13 & 38 \\
\hline Male, Cis, Homosexual & 4 & 62 & 6 & 28 & 38 & 42 \\
\hline
\end{tabular}


(cisgender majority) and sexual orientation (heterosexual majority). This trend is similar to that reported in research about undergraduate students from six universities in Canada regarding their experience of sexual violence [34].

\section{E. Job market}

The next analysis refers to the insertion of the physicists'community in the labor market. The question about professional occupation allowed multiple choices. This enables a combination of various responses, including high school (HS) teacher, university researcher, or lecturer (faculty, in the USA), temporary job [substitute (up to two years in Brazil), hourly, etc.], permanent job, position in a company or industry, autonomous, scholarship holder, or "without work or scholarship." Let us remark that public universities in Brazil are free of charges and tuition fees. Scholarship holders are students who earn a certain amount of support money for basic subsistence costs during their studies.

Table VI summarizes the occupational profile of respondents to the questionnaire. Almost half of the answers were from people who are lecturers or faculty and researchers in higher education. Of those who reported having multiple occupations, the most common combination refers to people who are high school (HS) teachers and university lecturers simultaneously. The numbers are given in Table VI, which also presents further details, with subdivisions for the cases "multiple occupation" and other. Noticeably, in this universe of responses we find a high percentage of people who accumulate functions: $13 \%$ of physicists work in more than one professional activity. Among them, there are 138 individuals who are HS teachers and university faculty, of which 50 specify (not shown in the table) that they are substitute teachers in HS.

TABLE VI. Occupational profile of respondents. Abbreviations same as in Fig. 7.

\begin{tabular}{llrr}
\hline \hline Occupation & & \multicolumn{2}{c}{ Number } \\
\hline T/R-HE & & & 845 \\
SH & & 323 \\
T-HS & & 77 \\
Other & Company or industry (CI) & 24 & 103 \\
& Autonomous (A) & 7 & \\
& HS substitute & 16 & \\
& Temporary (T) & 26 & \\
& Permanent & 30 & \\
MO & HE + HS & 138 & \\
& HE + HS + SH + A & 11 & \\
& SH + (T or A) & 17 & \\
& T $+($ CI or A) & 4 & \\
WW/WS & & & 115 \\
Total & & & 1676 \\
\hline \hline
\end{tabular}

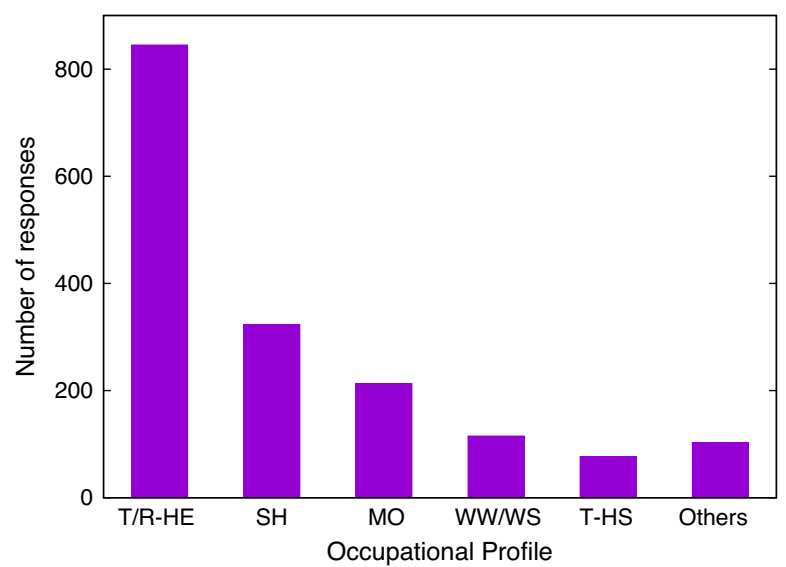

FIG. 7. Distribution of occupation of the respondents. The initials in the abscissa axis correspond to the following categories: lecturers and/or researchers in higher education institutions (T/R-HE), scholarship holders (SH), multiple occupations (MO), without work nor scholarship (WW/WS), high school teachers (T-HS).

This high percentage of people who accumulate positions deserve attention, and is plausibly related to underpaid positions. We also investigated the profile of unemployed people in the physics community and verified that, among the 115 respondents in the subgroup of without work or scholarship, 43 have HS as the highest level of education and 40 have a doctoral degree as the highest level. Normalizing these numbers by the total respondents in each one of these categories, given in Table I, we conclude that only $3.6 \%$ of the total respondents with a doctorate are unemployed, while around $41 \%$ of the undergrad students do not have scholarship.

More than half of the total of respondents works in higher education, as shown in Table VI. Let us take a closer look within this group. The data are not shown in the tables (for further information see Ref. [35]). In this universe, 95\% have a doctorate, $29 \%$ are female, which is slightly lower than the percentage of female respondents (which is $32 \%$ ). In the clipping of race or ethnicity, we found a clear privilege of self-declared white respondents over selfdeclared parda and black respondents: $67 \%$ of the respondents are white and only $16 \%$ parda and $4 \%$ black. When the responses about bearing children are evaluated, there is an important difference with regards to the sex of the respondents working in higher education. Among the male respondents $65 \%$ have at least one child, while among women only $44 \%$ have at least one child. This difference suggests that females in higher education institutions needed or chose to give up having children more than their male counterparts.

\section{SUMMARY AND FINAL REMARKS}

In this paper we have presented the results of a survey applied in the community of physicists who are members of 
the Brazilian Physical Society, with the main goals of addressing the following questions: How diverse is the physics community? What attracts people to follow this career? Which are the main difficulties to become a physicist? To what extent is sexual and moral harassment a problem in this community? How are physicists placed in the labor market? In this section we highlight some of our findings.

The first striking point is that the Brazilian Physical Society is not diverse in any way, as shown in Sec. IVA: it is made up of men $(68 \%)$, white $(61 \%)$, heterosexual $(88 \%)$, and southeastern $(59 \%)$ people, in a country where black and parda people, as well as women, are majority $[21,36]$. Moreover the diversity decreases with the progression in the career: percentages of women and black and parda people is higher among undergraduate students than at the $\mathrm{PhD}$ level, as shown in Fig. 3.

We have asked about the motivations to study physics and identified that there are two main drives to pursue this career (Sec. IV B): the ability to handle math and physics at school strongly influences this decision for $68 \%$ of the respondents, and around $62 \%$ of the respondents point to the hope of contributing to the progress of science. Approximately $80 \%$ of people attribute little or no influence of "social or financial recognition" for choosing a career in physics. These results point to a lack of recognition of scientific careers in the Brazilian society.

With regards to the difficulties in career advancement (see Sec. IV C), socioeconomic vulnerability was identified as the main obstacle at the beginning of the career. Other factors received a low number of answers, but this seems to be associated with the fact that they are important only for "minorities," as shown in Table II. The social class dimension is one of the most important aspects to be considered in order to understand the lack of diversity in physics and the segregation of our society. In basic education, more than $80 \%$ of Brazilians attend public schools [37], which has numerous deficiencies. Because private schools are expensive and the places in the public universities are limited to the ones who are able to succeed in a competitive test, people from middle and lower social classes, when they succeed entering the universityusually through quotas that exist for a decade only-they face enormous difficulties. On the one hand, follow-up policies are lacking in the universities and, on the other hand, the discourse of meritocracy, which assumes equal opportunities, is very strong in the physics community.

A worrying result (presented in Sec. IV D) concerns the very high percentage of moral harassment in the physics community: $38 \%$ of the respondents reported to have suffered moral harassment and it is more prevalent among women, being reported by $52 \%$ of the female respondents and by $31 \%$ of male respondents. Concerning sexual harassment, the total percentage is $12 \%$. In this case the gender difference is more striking: $32 \%$ of the female respondents reported being a victim of sexual harassment, while only $2 \%$ of men reported this problem.

In general, we observe a higher incidence of moral and sexual harassment in subgroups away from the majority response profile regarding gender identity (cisgender majority) and sexual orientation (heterosexual majority). These expressive percentages are in line with recent international reports [38-40].

As discussed in Sec. IV B, about $6.2 \%$ of the respondents declared to be careers of specific disabilities. Further studies and more specific surveys should be carried out to investigate more deeply other aspects possibly neglected in the present work.

Let us mention that recent studies have identified an extremely high concentration of mental problems in academia: in Ref. [41], the authors reported that graduate students are more than six times as likely to experience depression and anxiety as compared to the general population. Moreover, they found that both transgender or gender-nonconforming and female graduate students are significantly more likely to experience anxiety and depression than their male graduate student counterparts. The incidence of these mental problems depending on antecedents of sexual and moral harassment in academia remains to be investigated, but certainly these results are an alert for the institutions.

Looking for literature about problems faced by the community, we note a survey [42] that puts into evidence a source of unsatisfaction nowadays, which is the pressure to publish and its bad consequences.

Last, our survey allowed us to investigate some characteristics of the labor market for physicists in Brazil, as shown in Sec. IV E. We have identified that most of the respondents who have a Ph.D. in physics are employed (see Table VI): only $3.5 \%$ of doctors who responded are out of work. On the other hand, $12 \%$ of physicists work in more than one place and also there are $37 \%$ of undergraduate students without scholarships. By studying in detail the population who is unemployed or without scholarship, a bias in terms of color or gender was not found. However, we did identify that $60 \%$ of men working in higher education have children, while only $40 \%$ of women do. This expressive difference suggests that more women had to give up motherhood rather than men had to give up fatherhood, which is similar to the data reported in Ref. [43].

The present study brings results that may have implications not only for thinking about historical and philosophical aspects of science education, but also for reflecting on the potential that diversity develops in the production of valid knowledge. Although we recognize that some effort has been made in Brazil to increase the number of underrepresented people in the academic environment over the last 15 years, extra commitments are still required in dealing with the social exclusion and apartheid system 
in sciences, specifically in physics, where the numbers reveal high levels of inequality. We hope that the results presented and discussed in this paper can serve our community to be aware of the current scenario, and for policymakers to take decisions towards the improvement of diversity, equity, and inclusion, making the environment for physics learning and research more motivating and healthy, increasing the feeling of belonging to underrepresented groups.

The survey and a complete report can be found at the SBF website [35] and is available in Portuguese only. The translation of the survey to English is presented in the Appendix.

\section{ACKNOWLEDGMENTS}

The authors thank all anonymous respondents for answering the survey and the Sociedade Brasileira de Física (SBF) board and staff support. We are also grateful to the members of the Working Group of Underrepresented People of the SBF for their comments and suggestions.

\section{APPENDIX: APPENDIX-QUESTIONNAIRE}

"The Working Groups of the Brazilian Physical Society (SBF) about Gender and Underrepresented groups have made efforts towards a more inclusive and egalitarian physics community in Brazil. In order to know better the diversity of the physics community in what concerns age, race, ethnic origin, sexual orientation and special need issues, we invite you to answer this questionnaire. Our aim is to collect information that can contribute to the promotion of actions and policies that help decrease the access, career and promotion barriers, especially of those historically underrepresented groups in our community. All answers will be treated with anonymity. We thank your participation."

\section{Demographic characterization}

- Year of birth (4 digits):

- Brazilian State (2 letters) or country of birth (3 letters):

- Brazilian State (2 letters) or foreign country (3 letters) in which you currently reside:

- Do you have children? How many?

I do not have

Yes, 1

Yes, 2

Yes, 3

Yes, 4 or more

- If you have children, when were they born (in relation to the doctoral period)?

Before

During

After

\section{a. Academic training}

- What is the maximum academic level you have completed?

High school

Graduation

Bachelor's degree

Master's degree

Doctorate degree

- Year of completion of the highest level (4 digits):

\section{b. Professional occupation}

- Indicate all options that apply:

High school teacher

Higher education researcher or lecturer or faculty

Temporary job (temporary teacher, hourly, etc.)

Effective job

Work in company or industry

I work autonomously

Scholarship holder (types of scholarship: initiation to research, Master's, Doctorate and post-doc)

Without work or scholarship

\section{c. Color or race}

- What is your color or race?

Asian

White

Indigenous

Parda

Black

Other

I prefer not to classify myself

I prefer not to answer

- If you have answered "other," please specify.

\section{d. Sex and gender}

- What is your sex?

Female

Male

Other

- If you have answered "other," please specify.

- What is your gender identity?

Cisgender woman (1)

Cisgender man (1)

Transsexual or Transgender woman (2)

Transsexual or transgender man (2)

Non-binary (3)

Other

I prefer not to classify myself

I prefer not answer

- If you have answered "other," please specify.

(1) If you identify yourself with the sex assigned at birth. (2) If you have another gender identity other than that assigned at birth. (3) If you do not define 
your gender identity within the binary system man-woman.

\section{e. Sexual orientation}

- What is your sexual orientation?

Heterosexual

Homosexual

Bisexual

Pansexual

Asexual

Other

I prefer not to classify myself

I prefer not to answer

- If you have answered "other," please specify.

\section{f. Disabilities}

- Do you have any disability? Which one?

No

Low or abnormal vision

Blindness

Deafness

Physical

Intellectual

Global Developmental Disorder (2)

Other

(2) Autism, Rett Syndrome, Heller Syndrome, Asperger's Syndrome or Global development without further specification.

\section{Motivations}

a. Indicate how much you identify yourself with the following motivations to choose the area of physics:

- Affinity for physics at school

Very

Little

Not at all

- Easiness for math at school

Very

Little

Not at all

- Ease at passing the entrance exam

Very

Little

Not at all

- Close model (e.g., relative, friend, teacher)

Very

Little

Not at all

- Model at the cinema

Very

Little

Not at all
- Model in the literature

Very

Little

Not at all

- News in the media (outreach program)

Very

Little

Not at all

- Remuneration

Very

Little

Not at all

- Social Recognition

Very

Little

Not at all

- To participate in the progress of science

Very

Little

Not at all

- Other

Very

Little

Not at all

- If you have answered "other," please specify.

\section{Detecting difficulties}

- In comparison with your colleagues, how fast did you advance in your studies to reach the maximum level you have accomplished?

Faster

Same pace

Slower

I do not know

- In case your advancement was slower than the others, what do you think it was its main cause?

Age

Sex

Gender or sex orientation

Race or ethnic origin

Socioeconomic vulnerability

Disability

Chronic disease

Time to take care of small children

Time to take care of other family members

Marital situation

Does no apply

- In comparison with your colleagues with the same degree, how fast did you advance in your professional career?

Faster

Same pace

Slower 
I do not know

Does no apply

- From the following reasons:

influenced my studies negatively;

influenced my career negatively;

it was a discrimination motive during my studies;

it was a discrimination motive at my employment;

I have already observed or have been aware of the discrimination of colleagues on the studies environment;

I have already observed or have been aware of the discrimination of colleagues on the employment environment,

indicate all the options that apply to you:

Age

Sex

Gender or sex orientation

Race or ethnic origin

Geographical origin

Disability

Religion

Socioeconomic vulnerability

Chronic disease

Time to take care of other family members

Marital situation

Marital status

Time to take care of small children

To be or have been a university entrance quota beneficiary

other

- If you have answered "other," please specify.
- In cases of discrimination, was there any support from the colleagues or the Institution to solve the problem?

Never

Yes, in some cases

Always

I do not know

Does not apply

- Do you think that the role played by the Institutions in the case of discrimination should be more active than it currently is?

Yes

No

Perhaps

- Have you ever suffered sexual harassment from someone hierarchically superior than you (boss, supervisor, teacher)?

Yes

No

- In cases of sexual harassment, please explain what happened.

- Have you ever suffered moral harassment from someone hierarchically superior than you (boss, supervisor, teacher) ?

Yes

No

- In cases of moral harassment, please explain what happened.

- Please, give suggestions or information that you believe to be relevant and were not contemplated in this survey.
[1] A. Alves-Brito, P. F. Spinelli, V. A. Cuambe, I. Cabral, J. Latas, and R. Doran, Astronomy for development in Portuguese-speaking countries, Nat. Astron. 3, 366 (2019).

[2] A. Saxena, Workforce diversity: A key to improve productivity, Procedia Econ. Finance 11, 76 (2014).

[3] V. Hunt, D. Layton, and S. Prince, Diversity Matters: McKinsey and Company Report (2015), http:// www.mckinsey.com/business-functions/organization/ourinsights/why-diversity-matters, accessed: 2019-25-11.

[4] K. W. Philips, How diversity makes us smarter, Sci. Am. 311, 42 (2014).

[5] A. W. Woolley, I. Aggarwal, and T. W. Malone, Collective intelligence and group performance, Curr. Dir. Psychol. Sci. 24, 420 (2015).

[6] Science policies in the European Union, Promoting excellence through mainstreaming gender equality: A report from the ETAN expert working group on women and science (2000), https://op.europa.eu/en/ publication-detail/-/publication/4d456ad0-abb8-41a29d21-dbd5381f1f4c/language-en.
[7] P. Freire, Pedagogia do Oprimido, 36a ed. (Edições Paz e Terra, Rio de Janeiro, 2003).

[8] United Nations recent Human Development Report, http:// www.hdr.undp.org/.

[9] IBGE, Síntese de indicadores sociais: uma análise das condições de vida da população brasileira, https:// biblioteca.ibge.gov.br/visualizacao/livros/liv101629.pdf (2018), accessed: 2019-25-11.

[10] IBGE, www.ibge.gov.br (2019), accessed: 2019-11-25.

[11] IPEA, Atlas da violência, http://www.ipea.gov.br/portal/ images/stories/PDFs/relatorio_institucional/190605_atlas_ da_violencia_2019.pdf (2019), accessed: 2019-25-11.

[12] UN, UN issues first report on human rights of gay and lesbian people, https://www2.ohchr.org/english/bodies/ hrcouncil/docs/19session/A.HRC.19.41_English.pdf (2011), accessed: 2019-25-11.

[13] V. Morcelle, G. Freitas, and Z. M. C Ludwig, From school to university: An overview on STEM (Science, Technology, Engineering and Mathematics) gender in Brazil, Quarks: Braz. Electronic J. Phys. Chem. Mater. Sci. 1, 1 (2019). 
[14] J. J. Arenzon, P. Duarte, S. Cavalcanti, and M. C. Barbosa, Women and physics in Brazil: Publications, citations and $H$ index, AIP Conf. Proc. 1517, 78 (2013).

[15] D. P. Menezes, C. Brito, and C. Anteneodo, Women in physics: Scissors effect from the Brazilian Olympiad of physics to professional life, arXiv:1901.05536 [Sci. Am. Brasil, 76 (2017)].

[16] N. C. Ferrari, R. Martell, D. H. Okido, G. Romanzini, V. Magnan, M. C. Barbosa, and C. Brito, Geographic and gender diversity in the Brazilian academy of sciences, Anais da Academia Brasileira de Ciencias 90, 2543 (2018).

[17] G. Bezerra and M. Barbosa, Mulheres na física no Brasil Contribuição de alta relevância, mas, por vezes, ainda invisível, in SBF: 50 Anos, pp. 130-133 (2017), http:// www.sbfisica.org.br/arquivos/SBF-50-anos.pdf.

[18] G. C. Finlay, The physical science study committee, School Rev. 70, 63 (1962).

[19] Brazilian Association for Research in Science Education (ABRAPEC), http://abrapecnet.org.br/wordpress/pt/aboutabrapec/, acessed: 2020-14-03.

[20] V Pesquisa Nacional de Perfil dos Graduandos das IFES, http://www.andifes.org.br/wp-content/uploads/2019/05/VPesquisa-Nacional-de-Perfil-Socioecon $\%$ C3\%B4mico-eCultural-dos-as-Graduandos-as-das-IFES-2018.pdf.

[21] https://educa.ibge.gov.br/jovens/conheca-o-brasil/ populacao/18319-cor-ou-raca.html, acessed: 2020-14-03.

[22] https://en.wikipedia.org/wiki/List_of_Brazilian_federative_ units_by_gross_regional_product.

[23] https://agenciadenoticias.ibge.gov.br/agencia-noticias/2012agencia-de-noticias/noticias/21206-ibge-mostra-as-cores-dadesigualdade, acessed: 2020-14-03.

[24] Gender in the Global Research Landscape Report, Elsevier, London, 2019, https://www.elsevier.com/researchintelligence/resource-library/gender-report.

[25] S. Bustingorry, E. Moro, and M. F. Laguna, Mujeres en Física en Argentina: un análisis estadístico comparativo dentro del CONICET, Anales AFA 30, 58 (2019), https:// anales.fisica.org.ar/journal/index.php/analesafa/article/ view/2237/2567, accessed: 2020-13-02.

[26] S. R. Rankin, Campus climate for gay, lesbian, bisexual, and transgender people: A national perspective, technical report (National Gay and Lesbian Task Force Policy Institute, Washington, DC, 2003).

[27] S. R. Rankin, G. Weber, W. Blumenfeld, and S. Frazer, 2010 State of higher education for lesbian, gay, bisexual and transgender people, https://www.campuspride.org/ wp-content/uploads/campuspride2010lgbtreportssummary .pdf.

[28] P. P.S. Antunes, Travestis envelhecem? (Annablume, São Paulo, 2013).
[29] Mapa dos assassinatos de travestis e transexuais no Brasil em 2017, https://antrabrasil.files.wordpress.com/2018/02/ relatc3b3rio-mapa-dos-assassinatos-2017-antra.pdf.

[30] https://educa.ibge.gov.br/jovens/conheca-o-brasil/ populacao/20551-pessoas-com-deficiencia.html See also https://agenciabrasil.ebc.com.br/geral/noticia/2015-08/ ibge-62-da-populacao-tem-algum-tipo-de-deficiencia.

[31] R. H. Tai, C. Qi Liu, A. V. Maltese, and X. Fan, Planning early for careers in science, Science 312, 1143 (2006).

[32] Behavior that demeans, humiliates, or embarrasses a person at work or at the environment of studies. When these behaviors become repetitive, they are defined as bullying. https://en.wikipedia.org/wiki/Harassment.

[33] A. E. Tenbrunsel, M. K. R. Rees, and K. A. Diekmann, Sexual harassment in academia: Ethical climates and bounded ethicality, Ann. Rev. Psychol. 70, 245 (2019).

[34] A. Martin-Storey, G. Paquette, M. Bergeron, J. Dion, I. Daigneault, M. Hébert, and S. Ricci, Sexual violence on campus: Differences across gender and sexual minority status, J. Adolescent Health 62, 701 (2018).

[35] Questionário, Diversidade e Inclusão 2018, http://www1 .fisica.org.br/gt-genero/images/RelatorioQuestionario-GT .pdf.

[36] https://educa.ibge.gov.br/jovens/conheca-o-brasil/populacao/ 18320-quantidade-de-homens-e-mulheres.html, accessed: 2020-16-03.

[37] http://download.inep.gov.br/educacao_basica/censo_escolar/ notas_estatisticas/2018/notas_estatisticas_censo_escolar_ 2018.pdf.

[38] The National Academies of Sciences Engineering Medicine, Sexual harassment of women: Climate, culture, and consequences in academic sciences, engineering, and medicine, Consensus Study Report (National Academies Press, Washington, DC, 2018).

[39] A Global Approach to the Gender Gap in Mathematical, Computing, and Natural Sciences, edited by C. Guillopé and M.-F. Roy, https://gendergapinscience.files.wordpress.com/ 2020/02/final_report_20200204-1.pdf, accessed: 202023-02.

[40] Y. Pourrat, B. Clavreul, and A. Béraud, Attentes et besoins des femmes scientifiques en France, EPWS/ECEPIE, 2019, http://ecepie.fr/wp-content/uploads/2019/11/EPWS_ ECEPIE-Survey-r\%C3\%A9sultats-France_2018.pdf, accessed: 2019-25-11.

[41] T. M. Evans, L. Bira, J. B. Gastelum, L. T. Weiss, and N. L. Vanderford, Evidence for a mental health crisis in graduate education, Nat. Biotechnol. 36, 282 (2018).

[42] https://www.enago.com/academy/experts-take-problemsfaced-scientific-community/.

[43] E. H. Ecklund and A.E. Lincoln, Scientists want more children, PLoS One 6, e22590 (2011). 